\title{
ACOMPANHAMENTO DA CARGA PARASITÁRIA INTESTINAL E DO MANEJO SANITÁRIO DE UM CRIATÓRIO DE PACAS
}

\section{MONITORING OF THE INTESTINAL TRACT PARASITE LOAD AND OF THE SANITARY MANGEMENT AT A PACA BREEDING FARM}

\author{
Vânia Maria França Ribeiro ${ }^{1^{*}}$ \\ Soraia Figueiredo de Souza ${ }^{1}$ \\ Nayara Moreira Pinto de Mesquita ${ }^{1}$ \\ Augusto Luiz Faino Alves ${ }^{1}$ \\ Francisco Glauco de Araújo Santos ${ }^{1}$
}

${ }^{1}$ Centro de Ciências Biológicas e da Natureza, Universidade Federal do Acre, Rio Branco, AC, Brasil *Autora para correspondência - vania.rib@uol.com.br

\begin{abstract}
Resumo
A criação de pacas (Cuniculus paca Linnaeus, 1766) vem se desenvolvendo em toda América Latina. Com o objetivo de acompanhar o manejo sanitário, determinar a prevalência de parasitas gastrointestinais de pacas criadas em cativeiro, sua carga parasitária e avaliar estratégias utilizadas em seus controles, entre os meses de novembro/2012 a junho/2013, amostras de fezes frescas no solo foram coletadas e analisadas, utilizando-se as técnicas de Willis Mollay e Hoffmann. Para quantificação, utilizou-se a câmera de McMaster. A leitura foi realizada em microscopia óptica, com objetivas de $25 \mathrm{x}$ e $40 \mathrm{x}$, as quais revelaram 21.433 ovos por grama de fezes (OPG), com média de 2.679,12 ( \pm 41,0) Strongyloides spp., e 3.325 OPG, com média de 415,6 $( \pm$ 57,0) Trychuris spp. Também encontraram-se 482.101 oocistos por grama de fezes (OOPG), com média $60.263( \pm 15,93)$ de Eimeria spp. e 51 larvas de Strongyloides spp., com média 6,3 $( \pm 6,86)$ larvas. Em uma única baia foram identificados dois ovos de Hymenolepis diminuta. Foi utilizado um anti-helmíntico (albendazol $10 \%$ ) e trimetropina associada à sulfadiazina, para combater a eimeriose. Conclui-se que o grande índice de infestação parasitária apresentado pelos animais, mesmo a despeito dos tratamentos antihelmínticos efetuados, pode estar associado com o índice pluviométrico apresentado, as condições físicas das instalações e a limpeza e higienização dos recintos de forma inadequada.
\end{abstract}

Palavras-chave: animal silvestre; nematoides; paca.

\begin{abstract}
Paca (Cuniculus paca Linnaeus, 1766) rearing has shown development in all Latin America countries. Fresh feces samples were collected from the soil and analyzed by Willis Mollay and Hoffmann's techniques, aiming at accompanying the sanitary management, determining the prevalence of gastrointestinal parasites, and their respective load, of pacas raised in captivity, and evaluating parasite control strategies, between the months of November/2012 and June/2013. A McMaster's camera was used for quantification. The reading was accomplished by optical microscopy with $25 \mathrm{x}$ and $40 \mathrm{x}$ lenses, which revealed 21,433 eggs per gram of feces (EPG), with an average of 2,679,12 $( \pm 41.0)$ Strongyloides spp., and 3,325 EPG, with average of $415.6( \pm 57.0)$ Trychuris spp. Besides, 482,101 oocytes per gram of feces (OPG) were found, with an average of 60,263 ( \pm 15.93$)$ Eimeria spp., and 51 larvae of Strongyloides spp., with an average of $6.3( \pm 6.86)$ larvae. Two eggs of Hymenolepis diminuta were identified in only one stall. An anthelminthic (albendazole 10\%) and trimethopim
\end{abstract}


associated with sulfadiazine were used to treat the disease. We concluded the great index of parasitic infestation presented by the animals, in spite of the anthelminthic treatments, can be associated with the rainfall rates observed, the physical conditions of the instalations, as well as the adequate cleaning and sanitization of the facilities.

Keyword: Nematodes; paca; wild animal.

Enviado em: 21 outubro 2014

Aceito em 27 agosto 2015

\section{Introdução}

A paca (Cuniculus paca) está entre as espécies mais intensamente caçadas na América Latina, principalmente por causa de sua carne, cotada como a mais apreciada entre todas as carnes de caça, tornando-se uma importante fonte de proteína animal para as populações rurais ${ }^{(1-3)}$. No centro da região sul do Brasil, como no estado de Santa Catarina, esta espécie já consta como ameaçada de extinção ${ }^{(4)}$.

A criação de animais silvestres é apontada como uma importante estratégia para a preservação da fauna, por meio da qual se busca garantir a manutenção da biodiversidade, contribuir para a conservação e, ao mesmo tempo, atender às necessidades nutricionais das populações rurais brasileiras ${ }^{(5)}$.

O parasitismo e a depredação são mecanismos de controle natural das populações, sendo o contrário quando estão em cativeiro, já que as cargas e frequências parasitárias podem afetar o comportamento produtivo e reprodutivo e com isso diminuir a produtividade das espécies em um sistema de produção. Dessa forma, os parasitas gastrointestinais causam grande perda na produção e na saúde do animal e as informações geradas nos laboratórios de diagnóstico ajudam no conhecimento das parasitoses, permitindo desenvolver programas de prevenção, controle e erradicação das mesmas ${ }^{(6)}$.

A importância de se determinar, na paca, gênero e ordem de parasitas gastrointestinais (PGI), assim como as cargas e percentagens de ovos de parasitas durante um ciclo anual, é poder estabelecer relações entre parasito e hospedeiro e planejar estratégias de controle de parasitismo, dirigidos a espécimes criados em cativeiro ${ }^{(7)}$. Além disso, cresce o interesse da sociedade em estudar tal espécie, pela possibilidade de aproveitá-la como fonte de proteína e geração de renda, por meio da comercialização de produtos, como pele, couro e pelos, que apresentam grande potencial de mercado ${ }^{(8)}$.

$\mathrm{O}$ ciclo evolutivo desses parasitas apresenta padrão comum quanto à eliminação de oocistos e ovos juntamente com as fezes dos animais parasitados, contaminando assim o solo onde são depositados os dejetos, com sua consequente disseminação no ambiente ${ }^{(9)}$.

Com vistas ao exposto, este trabalho teve como objetivo acompanhar o manejo sanitário, determinar a prevalência de parasitas gastrointestinais de pacas criadas em cativeiro bem como suas cargas parasitárias, relacionando com o índice de pluviosidade no período estudado e avaliar as estratégias utilizadas em seus controles.

\section{Material e Métodos}

O local de estudo foi o criatório de animais silvestres "Caboclinho da Mata", com registro no IBAMA número 509309, situado na Fazenda Experimental Catuaba, pertencente à Universidade Federal do Acre, localizada no município de Senador Guiomard Santos, km 30 da rodovia BR - $364\left(10^{\circ} 04^{\prime}\right.$ S e $\left.67^{\circ} 37^{\prime} \mathrm{W}\right)$. O clima é tipo amazônico equatorial quente e úmido, com temperaturas variando de $24,5^{\circ} \mathrm{C}$ a $32^{\circ} \mathrm{C}$, com duas estações, a estação seca, popularmente denominada de verão amazônico, sendo para a Amazônia, época de baixo regime fluvial, que se estende de junho a setembro, e a estação chuvosa, iniciando-se no mês de novembro, prolongando-se até o final de abril, época do ano 
popularmente denominada inverno amazônico, configurando-se, então, como época de alto regime fluvial na região ${ }^{(10)}$.

As coletas de fezes foram realizadas em oito baias de $12 \mathrm{~m}^{2}$ cada; em seis estavam alojados um macho e três fêmeas adultas e em duas outras, dois grupos de cinco filhotes / baia. Em cada baia, as amostras de fezes frescas no solo foram coletadas de forma coletiva, no período de 13/11/2012 a 28/06/2013, no horário de $5 \mathrm{~h} 30 \mathrm{~min}$, a cada 14 dias. Neste período, constataram-se tipos de ovos e oocistos, índice de parasitose, condições de alojamento dos animais, higienização dos recintos e avaliou-se a eficácia de anti-helmínticos utilizados pelos responsáveis do criatório nos animais.

Com relação ao manejo das baias, as instalações que abrigavam estes animais eram de chão batido com áreas irregulares. A higienização era realizada diariamente e eventualmente cal era aplicada na forma de pó.

Dezessete amostras no total foram coletadas e acondicionadas em frascos plásticos, devidamente etiquetados com o número da baia. Os frascos eram então imediatamente alocados em caixas térmicas contendo gelo, até que fossem transportados, e as amostras analisadas no Laboratório de Apoio à Vida Silvestres da Universidade Federal do Acre.

Para quantificação de ovos de helmintos (OPG), utilizou-se a câmara de McMaster e solução hipersaturada de $\mathrm{NaCl}$ (técnica de Willis Mollay). A carga parasitária dos protozoários (OOPG) foi quantificada mediante o uso de câmara de McMaster ${ }^{(11)}$, usando-se uma solução hipersaturada de açúcar (técnica de Willis Mollay). Para a identificação de ovos pesados, utilizou-se a técnica de Hoffmann. A leitura foi realizada em microscópio óptico, com objetivas de 25x e 40x. A morfometria dos ovos e oocistos foi obtida com ocular milimetrada KF10x.18 Carl, e a identificação pela comparação da morfometria encontrada como a de espécies descritas na literatura. Foi também efetuado registro fotográfico com câmera digital Sony, 16 megapixels, e os dados pluviométricos foram obtidos através do site: http://www.acrebioclima.pro.br/. Médias e desvios padrão foram efetuados com os dados obtidos utilizando-se o programa Excel 2010.

A eficácia dos tratamentos foi calculada por meio da seguinte fórmula: Eficácia(\%) $=1-[(\mathrm{OPG}$ médio pós tratamento/OPG médio antes do tratamento)] X 100, sendo o OPG médio = a média aritmética do OPG dos animais tratados ${ }^{(11)}$.

\section{Resultados e Discussão}

As análises das amostras demonstraram principalmente a presença de ovos de nematoides do gênero Trichuris spp. (Fig. 1a), Strongyloides spp. (Fig. 1b), larvas rabditóides do gênero Strongyloides spp. (Fig. 1c), além de oocistos de Eimeria spp. (Fig. 1d). Os ovos e oócistos encontrados foram também evidenciados nesta espécie por outros autores ${ }^{(7,13,14)}$. Efetuadas as medições nos ovos de nematoides encontrados, verificou-se que ovos de Strongyloides spp. possuíam em média de 57,14 $\mu \mathrm{m}( \pm 4,19)$ de comprimento e 30,35 $\mu \mathrm{m}$ de largura e os ovos de Trichuris spp. possuíam média de $60,3 \mu \mathrm{m}( \pm 6,68)$ de comprimento e media de $30 \mu \mathrm{m}$ de largura. Quanto aos protozoários, os oocistos de Eimeria spp. variaram entre tamanhos de $25 \mu \mathrm{m}$ a $12,5 \mu \mathrm{m}$ com média de $20,8 \mu \mathrm{m}( \pm 2,52)$ de diâmetro.

A carga parasitária evidenciada pela quantificação de ovos e oócistos, durante os meses estudados, encontra-se demonstrada nas Figuras 2 e 3.

A grande quantidade de ovos de nematoides e oocistos de Eimeria spp. observados no mês de novembro levou os responsáveis do criatório a utilizarem anti-helmínticos (albendazol 10\%) e fazer uso de trimetropina associada a sulfadiazina, para preservar a vida dos mesmos, uma vez que alguns animais começaram a apresentar diarreia. Strongyloides spp. e Trychuris spp. são nematoides que possuem relevante importância em Medicina Veterinária por ocasionar lesões pulmonares, emaciação, inflamação crônica intestinal e diarreia, quando em alta carga parasitária ${ }^{(15)}$. Com relação à observação de oocistos de Eimeria spp., estes parasitas em roedores, como coelhos, causam destruição das criptas no intestino, o que resulta em diarreia e emaciação ${ }^{(12)}$. 

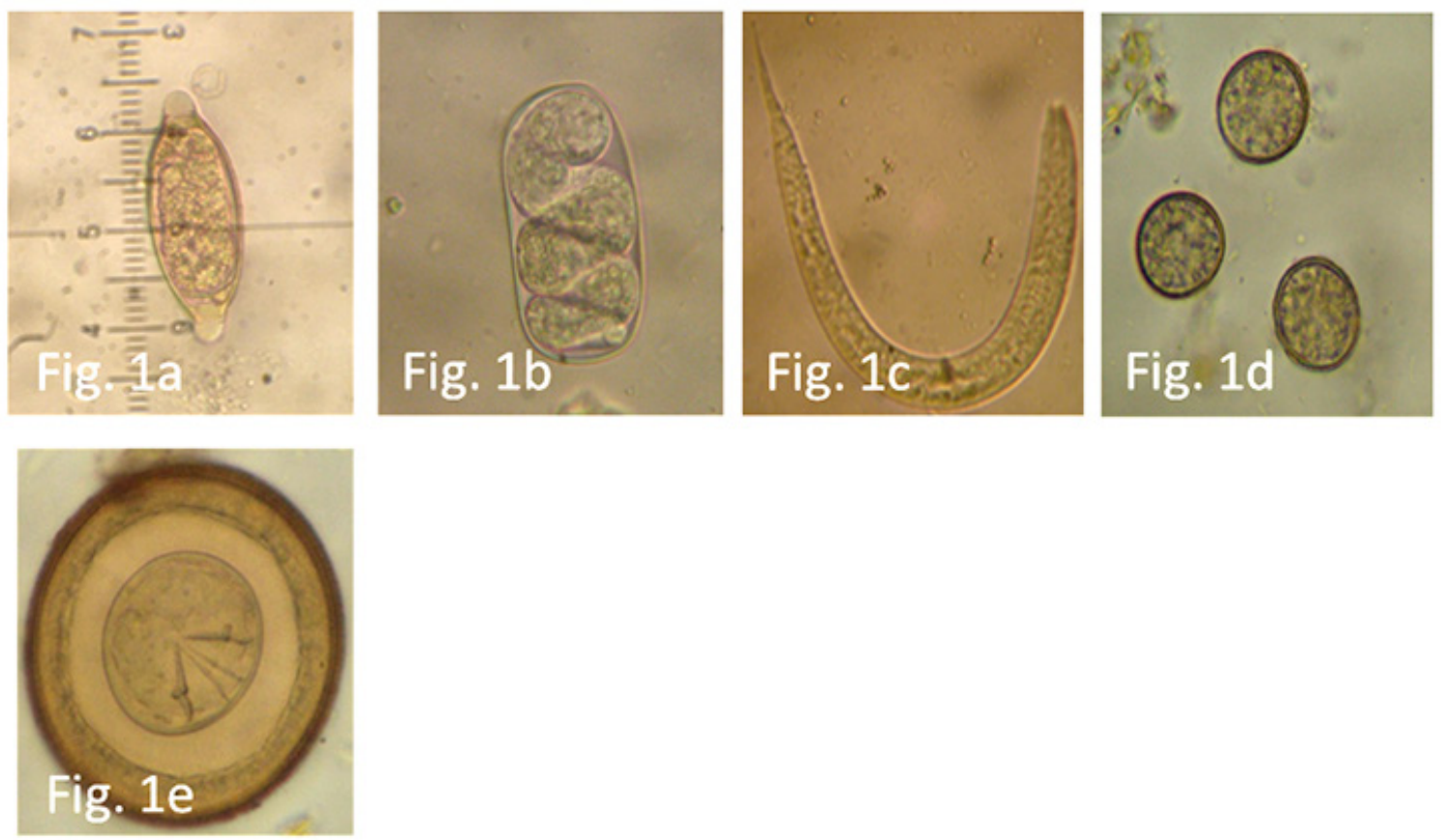

Figura 1: Tipos de ovos, larva de nematoides e oocistos de protozoário de pacas. 1a e 1b ovos dos gêneros Trichuris spp. e Strongyloides spp., respectivamente; 1c larva do gênero Strongyloides spp. (larva rabditóide), 1d. oocistos de Eimeria spp. não esporulado e 1e ovo de Hymenolepis diminuta.

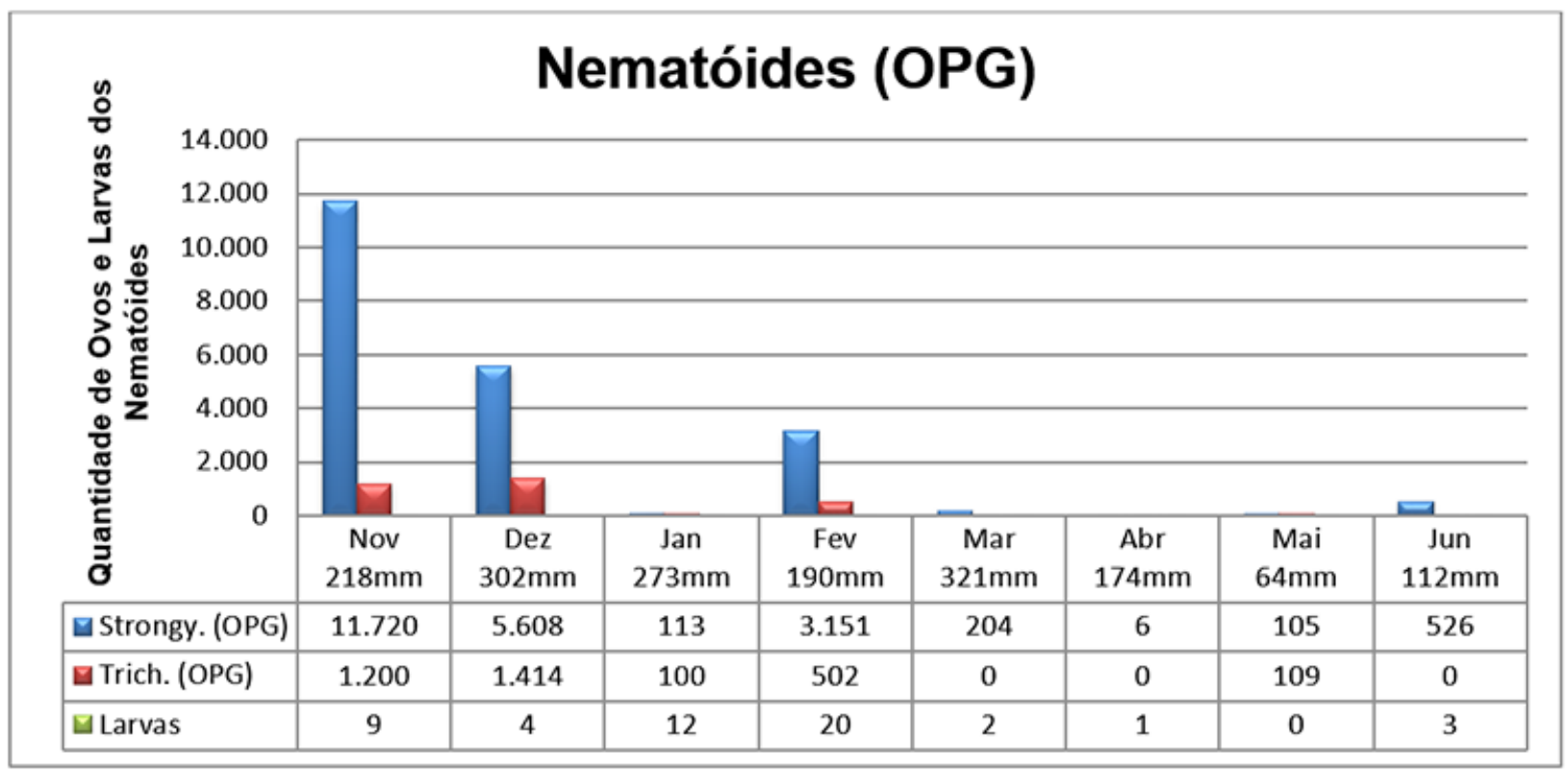

Figura 2: Quantidade de ovos e larvas de nematóides Strongyloides spp. e Trichuris spp., em cada mês de coleta, com suas respectivas pluviosidades médias, de pacas provenientes do criatório "Caboclinho da Mata", em Rio Branco-Acre. 


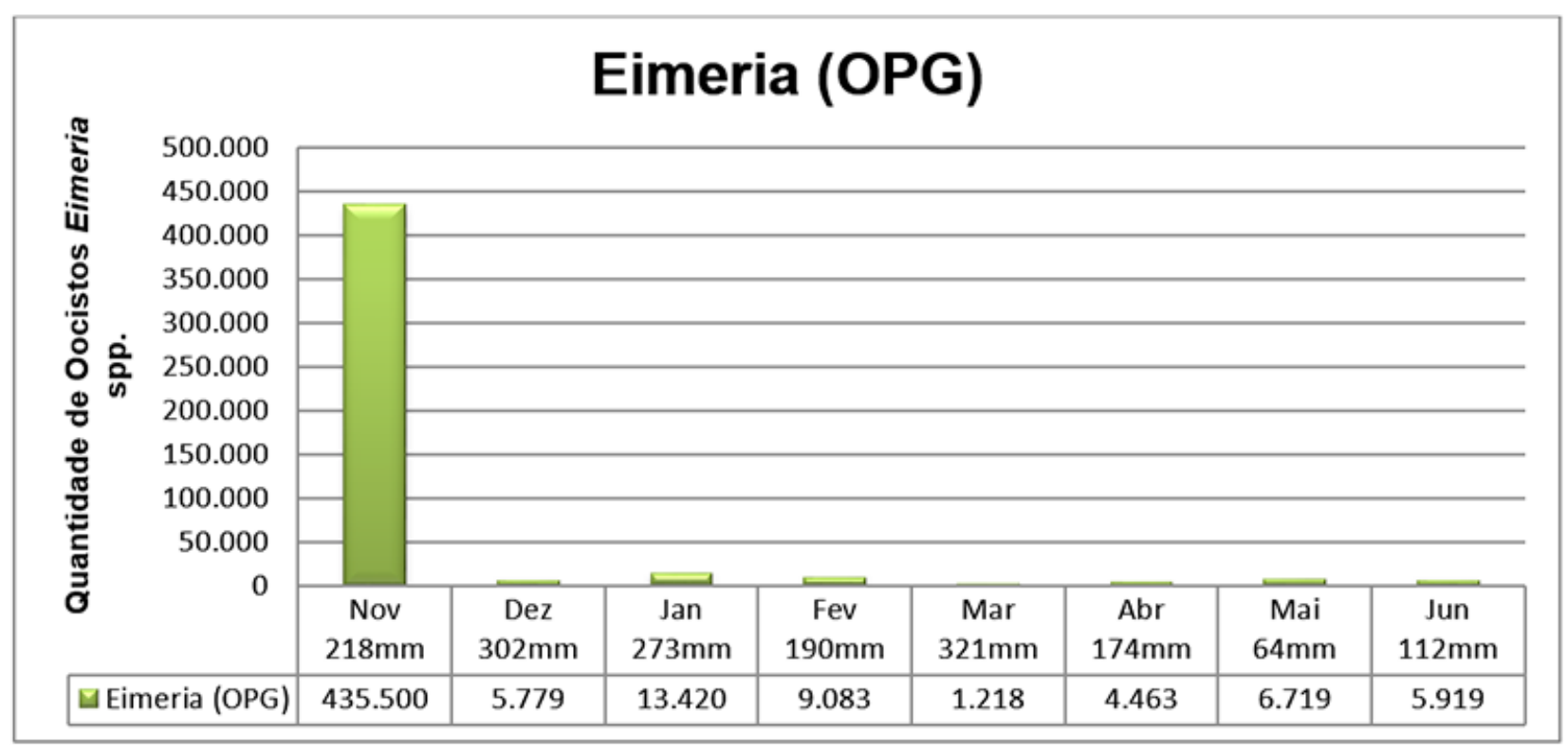

Figura 3: Quantidade de Oocistos de Eimeria spp., em cada mês de coleta, com suas respectivas pluviosidades médias, de pacas provenientes do criatório "Caboclinho da Mata", em Rio Branco Acre.

Como pode ser observado nas Figuras 2 e 3, provavelmente, ainda pelos efeitos dos medicamentos antiparasitários utilizados, houve redução dos ovos e oocistos encontrados no mês de dezembro. Com relação aos nematoides, uma nova everminação com albendazol 10\% foi efetuada em fevereiro com visível diminuição dos ovos encontrados em março. O mês de maio caracterizou-se por nova elevação dos gêneros Strongyloides e Trichuris, sendo que este último retornou a aparecer nas análises apenas em maio, o que não ocorria desde o mês de março. O gênero Trichuris pode causar sérios danos em monogástricos podendo provocar inflamação e sangramento do ceco, originando diarreia e anemia, sendo os animais jovens mais sensíveis a este parasita gastrointestinal ${ }^{(16)}$.

Nas últimas três coletas efetuadas no mês de junho, observou-se diminuição dos nematoides Trichuris spp. Já a quantidade de ovos e larvas de Strongyloides spp. neste mesmo mês apresentou leve aumento. Uma nova elevação de oocistos pôde ser observada em janeiro, fazendo com que houvesse repetição do tratamento anterior à base de trimetropina associada a sulfadiazina, cuja ação pôde ser observada com a redução de oocistos no mês de fevereiro. Nos mês de abril, ocorreu novo aumento de oocistos de Eimeria spp., embora os animais tenham sido tratados com os coccidiostáticos acima mencionados. Em maio houve repetição do tratamento, o que provavelmente resultou na leve diminuição de oocistos de Eimeria spp., observada nas ultimas três coletas efetuadas no mês de junho.

Os índices parasitários para ovos de nematoides e oocistos encontrados, apesar de terem sofrido uma baixa, continuaram elevados à despeito dos tratamentos efetuados. Este fator pode estar associado ao índice pluviométrico observado durante o período chuvoso (entre novembro e junho) estudado. A ocorrência da coccidiose é mais frequente nos períodos de maior pluviosidade, em locais mais úmidos e de higiene precária, pois isso favorece a sobrevivência dos oocistos infectantes, permitindo maior contaminação ambiental, dos alimentos e da água com as fezes dos animais ${ }^{(18)}$.

No Brasil, apesar da inexistência de estimativas oficiais, acredita-se que as perdas em produtividade decorrentes de endoparasitoses sejam elevadas, considerando-se que o clima da maioria das regiões brasileiras é favorável às mesmas ${ }^{(19)}$.

No criatório de pacas em estudo, foi observado que as instalações que abrigam estes animais são de chão batido e, na maior parte do tempo durante o período de chuva, mantêm-se com elevada umidade e, não raro, poças d'água. Já foi demonstrado haver associação entre a presença de lâmina d'água e 
parasitos da superfamília Strongyloidea ${ }^{(20)}$. Além disso, apesar de as baias serem limpas diariamente, observou-se que a única substância desinfetante utilizada é a cal que é aplicada na forma de pó e não em solução aquosa. Entretanto, outro estudo realizado com larvas de Strongyloides ratti e Strongyloides stercoralis já constatou que algumas substâncias como a cal, o iodo e o pentaclorofenato de sódio só tiveram ação letal sobre as larvas de Strongyloides ratti e Strongyloides stercoralis quando estas eram usadas em suspensão aquosa e, na presença do solo, aquelas substâncias tornaram-se inativas ${ }^{(21)}$. É provável que esta solução desinfetante na forma como vem sendo usada também seja ineficaz em oocistos de Eimeria spp. presentes no solo, o que permite a reinfestação pelos animais.

Foram também encontrados dois ovos de Hymenolepis diminuta (Fig. 1e), um medindo 82,5 $\mu \mathrm{m}$ comprimento X 69,37 $\mu \mathrm{m}$ de largura, e o outro $65,00 \mu \mathrm{m}$ de comprimento X 69,37 $\mu \mathrm{m}$ de largura (média: 65,62 $\pm 13,28$ ), em uma única baia ocupada por três fêmeas e um macho adultos. Os achados ocorreram nos meses de outubro (um) e dezembro (um), embora não se tenha verificado nenhuma sintomatologia clínica nestes animais. $H$. diminuta é o cestóide mais frequentemente encontrado em Rattus sp., o hospedeiro e reservatório natural, mas M. musculus e outros mamíferos, incluindo o homem e Chaetomys subspinosus e Sphiggurus villosus podem igualmente ser infectados por este parasita $^{(22-24)}$. Em Cuniculus paca este é o primeiro relato.

No Acre, a estação de seca se estende de junho a setembro ${ }^{(10)}$. Entretanto, o mês de junho apresentou índices pluviométricos maiores até que o mês de maio, o que provavelmente favoreceu o aumento de OPG de nematoides e a permanência elevada de Eimeria spp. nas fezes destes animais durante este período mesmo com tratamento anti-coccidiostático efetuado em maio.

\section{Conclusão}

O grande índice de infestação parasitária apresentada pelos animais, mesmo a despeito dos tratamentos anti-helmíntico e anti-coccidiostático efetuados, pode estar diretamente associado com o índice pluviométrico apresentado, às condições físicas das instalações (permitem acúmulo de água no solo), como também à limpeza e higienização dos recintos de forma inadequada.

Espera-se que, com os resultados obtidos, possa-se traçar um plano de manejo que, de forma mais eficaz, contribua para a diminuição e controle de parasitoses intestinais de pacas na Amazônia ocidental.

Além disso, novos estudos devem ser efetuados como o acompanhamento da carga parasitária intestinal de pacas nos períodos mais secos do ano bem como o teste de outros produtos químicos desinfetantes ou a utilização da cal virgem em solução aquosa para que se possam inativar os ovos e oocistos no solo e assim interromper o ciclo biológico destes parasitas.

\section{Referências}

1. Valsecchi J, Amaral PV. Perfil da caça e dos caçadores na reserva de desenvolvimento sustentável Amanã, Amazonas- Brasil. Uakari. 2009 dez; 5(2):33-48.

2. Chiarello A G. Influência da caça ilegal sobre mamíferos e aves das matas de tabuleiro do norte do estado do Espírito Santo. Bol Mus Biol Mello Leitão. 2000; 11/12:229-247.

3. Bonatelli M, Carter AM, Machado MRF, De Oliveira MF, De Lima MC, Miglino MA. Placentation in the paca (Agouti paca L). Reprod Biol Endocrinol. 2005. p 2.

4. Spezia MB, Grasel D, Miranda GB. Inventário rápido de mamíferos não voadores em um fragmento florestal do bioma mata atlântica. Unoesc \& Ciência.2013 jul./dez. 5(2):145-154.

5. Souza BCS, Santos GA, Campos RML. Carne de jacaré. Rev Eletr Nutritime, artigo 277. 2014; 11(6):37413754.

6. Rodríguez-Vivas RI, Cob-Galera AL, Domínguez-Alpizar JL. Frecuencia de parasitos gastrointestinales en animales domésticos diagnosticados en Yucatán, México. Rev Biomed. 2001; 12: 19-25. 
7. Ramírez-Herrera O, Rodríguez-Vivas IR, Montes-Pérez R, Torres-Acosta FJ. Seguimiento anual de la parasitosis gastrointestinal del tepezcuintle, Agouti paca (Rodentia: Agoutidae) en cautiverio en el trópico mexicano. Rev Biol Trop. 2001; 49:1171-1176.

8. De Medonça IL, De Almeida MM, Conde Júnior AM, Cavalcante RR, De Moura SG, Carvalho MAM. Análise coproparasitológica de cutias (Dasyprocta sp.) criadas em cativeiro. Ciên Anim Bras. 2006; 7(3):286.

9. Matesco VC, Rott MB, Mentz MB. Comparação entre métodos de centrífugo flutuação utilizados para a recuperação de ovos de helmintos em amostras de areia. Rev Patol Trop. 2011 out.- dez; 40 (4):323-330.

10. Santi GM, Furtado CM, De Menezes RS, Keppeler EC. Variabilidade espacial de parâmetros e indicadores de qualidade da água na sub-bacia hidrográfica do igarapé São Francisco, Rio Branco, Acre, Brasil. Ec. Aplic. 2012; 11(1):24.

11. Melo ACFL, Bevilaqua CML, Selaive V, Girão MD. Resisgência a anti-helmínticos em nematóides gastrintestinais de ovinos e caprinos, no municipio de Pentecoste, Estado do Ceará. Cienc Anim. 1998, 8(1):711.

12. Soave GL. Anticoccidianos em rações. Rev Eletr Nutritime, artigo 128. 2011; 8(1):1401-1417.

13. Matamoros Y. Anatomia e histologia del sistema reprodutor del tepezcuinte (Cuniculus paca). Rev Biol Trop. 1981; 29:155-156.

14. Pinto MR, Knoff M, Gomes DC, Noronha D. Nematodes from mammals in Brazil: an updating. Neotrop Helminthol. 2011; 5(2): 139-184.

15. Tavela AO, Souza TD, De Araújo GR, Braga RF, Garay RM, Da Silva CL, et al. Identificação de endoparasitas de quatro pacas (Cuniculus pacas) (LINNAEUS, 1766) oriundas da zona da mata da mata mineira. In: IX SIMPOSIO de veterinária da Universidade Federal de Viçosa - MG, 8., 2009.

16. Soulsby EJL. Parasitología y enfermedades parasitarias de los animales domésticos. Nueva Interamericana, México, D.F., 1987. p 823.

17. Daugschies A, Najdrowski M. Eimeriosis in cattle: current understanding. J. Vet. Med. B, Infect. Dis Vet Pub Health. 2005; 52(1): 417-427.

18. Azevedo DMMR, Alves AA, Sales RO. Principais Ecto e Endoparasitas que Acometem Bovinos Leiteiros no Brasil: Uma Revisão. Rev. Bras. Hig. Sanid. Anim. 2008; 2 (4): 43-55

19. Nishi SM, Gennari SM, Lisboa MNTS, Silvestrim A, Caproni JR A, Umehara O. Parasitas intestinais em suínos confinados nos estados de São Paulo e Minas Gerais. Arq Inst Biol, São Paulo. 2000 jul./dez.; 67 (2):199-203.

20. Chaia G, Pauline E. Ação do 0,0-Dimetilfosfato do 1-Hidroxi-2,2,2-Tricloro-Etila (Dipterex) Sobre as larvas de Strongyloides Ratti e Strongyloides Stercoralis. Rev Inst Med Trop São Paulo. 1962 Julho-agosto; 4(4):256-260.

21. Kuniy AA, Brasileiro MTR. Occurrence of h elminths in Bristle-spined Porcupine (Chaetomys subspinosus) (OLFERS, 1818), Salvador, Brazil. Braz J Biol. 2006; 66(1B):379-380.

23. Pakdel N, Naem S, Rezaei F, Chalehchaleh A. A survey on helminthic infection in mice (Mus musculus) and rats (Rattus norvegicus and Rattus rattus) in Kermanshah, Iran. Vet Res Forum.2013; 4(2): 105-109.

24. Guimarães GC, Lopes GC, Rosa MCB, Sestari CEO, Oliveira FS. Lobação pulmonar e distribuição brônquica do ouriç̧o-cacheiro (Sphiggurus villosus). Acta Sci Vet. 2012; 40(2):1037. 